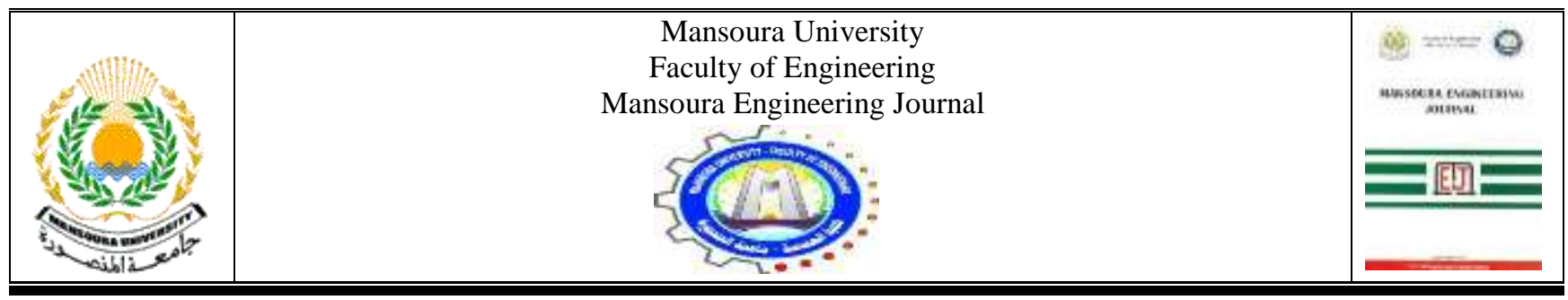

\title{
Theoretical and Experimental Investigation on Different Parameters Affecting Heat Pipe Performance Charged with R-22

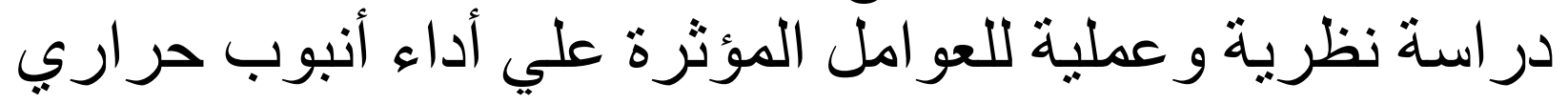

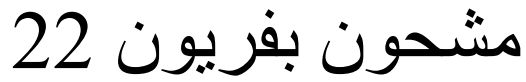

\author{
Sultan A. A, El-Bouz A. M, Semary N. A and Kandil M. E
}

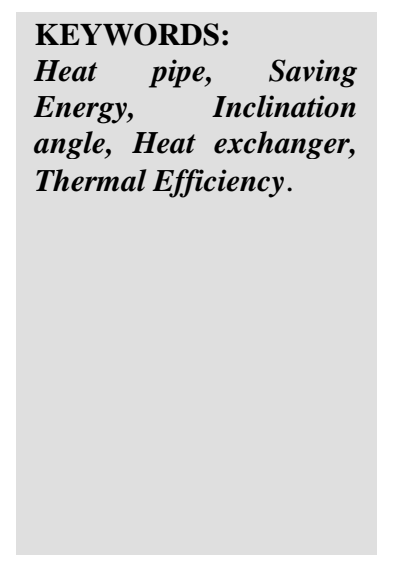

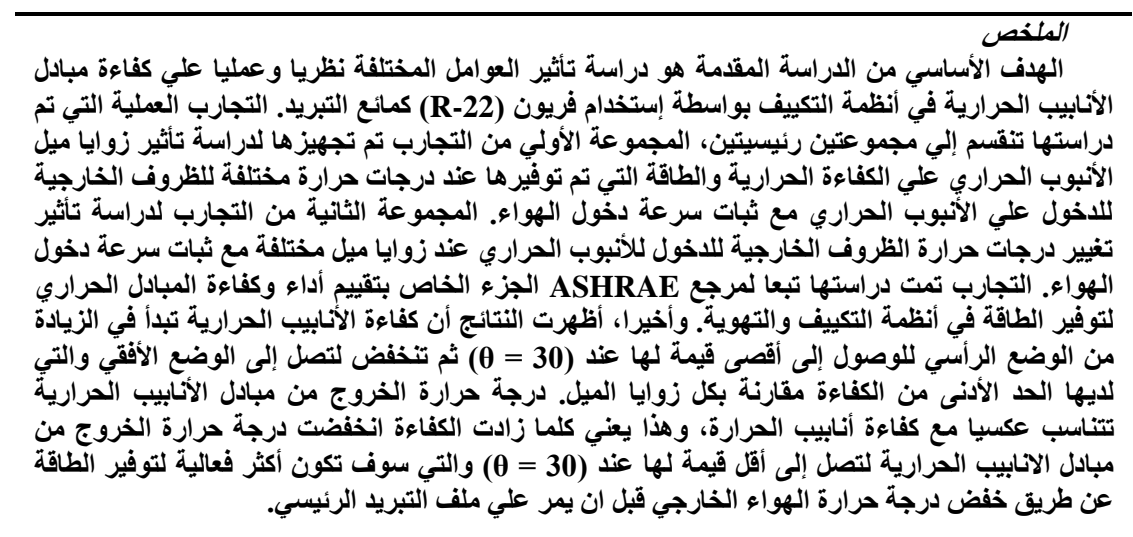

الهدف الأساسي من الدراسة المقدمة هو دراسة تأثير العوامل المختلفة نظريا وعمليا علي كفاعة مبادل

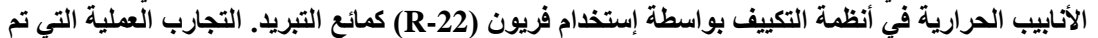

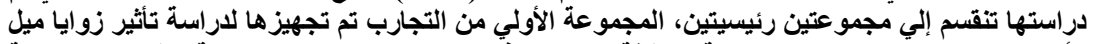

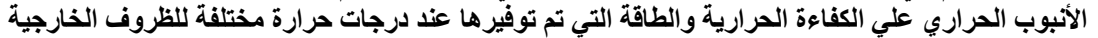

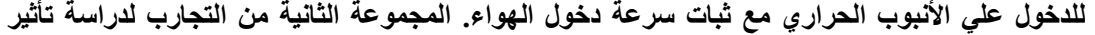

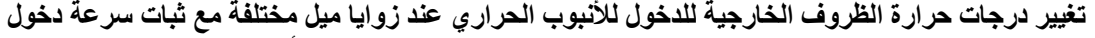

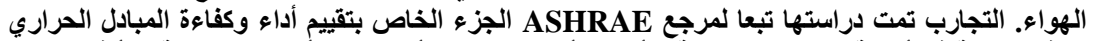

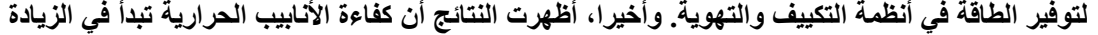

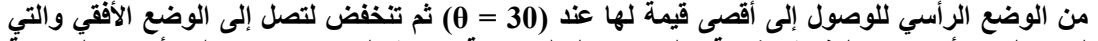

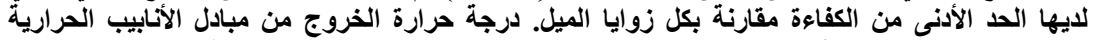

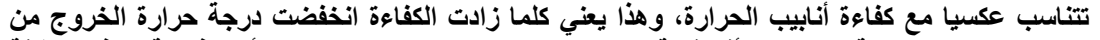
عن طريق خفض درجة حرارة اللهواء الخارجي قبل التبل ان يمر علي ملف ألتبريد الرئيسي.

Abstract - The present work was carried out theoretically and experimentally to study the performance enhancement of the heat pipe charged with refrigerant $(\mathrm{R}-22)$ as a working fluid. The heat pipe heat exchangers are used in heat recovery applications to cool the incoming fresh air in air conditioning systems. The study discusses the effect of inclination angle and supply on

Received: (19 December, 2016) - revised: (11 May, 2017) - accepted: (19 November, 2017)

Ahmed Abdel Razik sultan, He is with the Mechanical power Engineering Department, Mansoura University, (e-mail: ahmed sultan@yahoo.com).

Ali Mostafa ElBouz. He is with the Mechanical power Engineering Department, Mansoura University, (e-mail: profelbouz@yahoo.com).

Semary $N$, is with the Mechanical Engineering Department, MUST University, HVAC consultant Engineer (e-mail: profnabihsemary@gmail.com).

Kandil M. E, is Senior MEP Technical office engineer, Hassan Allam Holding, (e-mail: mhammedkandil@gmail.com). temperature on thermal efficiency, supply off temperature (T2), thermal resistance and heat recovered of the heat pipe heat exchanger. Two streams of fresh and return air have been flowed through the heat pipe heat exchanger to investigate the performance of heat recovery system. The heat pipe heat exchanger is consisting of one row of 16 copper tubes and aluminum fins. The diameter of each copper tube is $9.53 \mathrm{~mm}$. The experiments were performed due to ASHRAE standard 1060 (I-P) for performance rating of air-to-air exchangers for energy recovery ventilation equipment [1]. The results showed that Heat pipe efficiency and heat recovered capacity are increased by increasing the inclination angle until reach its maximum values at $\left(\theta=30^{\circ}\right)$ and then decreased with further increase in inclination angle. The results showed also that the thermal efficiency and heat-recovered capacity are increased by increasing the supply on temperature. 


\section{INTRODUCTION}

$\mathrm{H}$ EAT pipe is a heat transfer device that transports large quantities of heat with minimum temperature gradient without any additional power between the two temperature limits. It consists of three different sections namely evaporator, adiabatic section and condenser section. These three parts have equal importance and can significantly affect the performance of heat pipe. The heat input is added to the evaporator section of the heat pipe, the working fluid present in the wicking structure which is kept in the heat pipe is heated until it vaporizes. Since the latent heat of evaporation is large, considerable quantities of heat can be transported with a very small temperature difference from end to end. Thus, the structure will also have a high effective thermal conductance. Due to high temperature and high pressure that effect on the evaporator section cause the vapor flow to the cooler condenser section, where the vapor condenses and releases its latent heat of vaporization. The capillary forces existing in the wicking structure then pump the liquid back to the evaporator. The evaporator and condenser sections of a heat pipe function independently, needing only common liquid and vapor streams [2]. Samman [3] studied the possible application of a Heat pipe heat exchanger (HPHX) for indirect evaporative cooling with heat recovery for the fresh air preheating. In this study, the thermal performance of a HPHX consisting of 48 wicked heat pipes arranged in 6-row was tested. McFarland et al. [4] have investigated an experiment to determine the effect of a heat pipe on the performance of a conventional residential air conditioning system. In this study, the influence of heat pipe on the moisture removal, and the latent energy efficiency ratio of the air conditioning system were examined. L. Shao and Riffat [5] investigated the flow loss caused by a HPHX in a natural ventilation stack. Experimental results showed that for a heat recovery efficiency of $50 \%$ and stack flow velocity of $0.5 \mathrm{~m} / \mathrm{s}$, the pressure loss across an existing type of heat pipe was about one Pascal. Martinez et al. [6] designed a mixed energy recovery system consisting of two heat pipes heat exchanger and indirect evaporative cooler for air conditioning. The energy characterization of the mixed energy recovery system was performed by means of the experimental design techniques. Riffat and Zhu [7] introduced a mathematical model for a new technique of indirect evaporative cooler using porous ceramic and horizontal configuration heat pipe. The system had two separate air passages, one for indoor air and another for outdoor air. In this system, the heat applied to one end of the pipe (evaporation section) makes the liquid working fluid evaporates and the resulting vapor travels to the cooled end (condenser, or the ceramic container), where it condenses. Mostafa A. Abd El-Baky et. al. [8] conducted a study on the use of heat pipe for heat recovery in air conditioning. Two streams of fresh and return air have been connected with heat pipe heat exchanger to investigate the thermal performance and the efficiency of heat recovery system. The results showed that the temperature changes of fresh and return air are increased with the increase of inlet temperature of fresh air.
Tushar and Mandar [9] investigated the energy saving and dehumidification enhancement aspects of HPHXs and made a summary of experimental and theoretical studies on HPHXs. The following cases are studied. Case I: Varying the return air DBT between 21 and $25{ }^{\circ} \mathrm{C}$, keeping RH constant at $50 \%$. Case II: Varying the return air RH between $45-55 \%$ keeping DBT constant at $23{ }^{\circ} \mathrm{C}$.

Beckert and Herwig [10] carried out a research on the impact of inclination on the heat transfer rate of an air-to-air HPHX applied in an air conditioning system. It was found that even in a nearly horizontal position (up to $\pm 6^{\circ}$ with the horizontal) the overall performance is still good enough. Said and Akash [11] studied the effect of tilt angle on the overall heat transfer of two types of heat pipes, one with wick and another with no wick. The heat pipes were positioned at different tilt angles of $30^{\circ}, 60^{\circ}$, and $90^{\circ}$ with the horizontal. Kim et al. [12] carried out a research on the effect of air inlet humidity on the air side heat transfer and pressure drop for an inclined brazed aluminum heat exchanger. The heat exchanger was studied at three different inclined angles namely $14^{\circ}, 45^{\circ}$, and $67^{\circ}$ (with respect to vertical position). Yau [13] claimed that the impact of condensate layer on the performance of a thermosyphon HPHX operating in a high humid condition was negligible. In case of inclination angle of $30^{\circ}$ with horizontal, the gravitational force would be expected to enhance drainage of any condensate on the fin surfaces in evaporator section. Senthilkumar et. al. [14] conducted a study on effect of tilt angle on heat pipe performance using copper nanofluid. An experiment was carried out to study the thermal efficiency enhancement of the heat pipe using copper nanofluid as the working fluid. The study was performed for studying the effect of tilt angle and heat input on both thermal efficiency and thermal resistance.

The aim of the present work is to study the effect of inclination angle, supply on temperature and airflow rate on the heat pipe heat exchanger performance in HVAC systems especially on thermal efficiency, supply off temperature $\left(T_{2}\right)$, thermal resistance and heat recovered of the heat pipe heat exchanger.

\section{THEORETICAL ANALYSIS}

We discuss how we can make a theoretical design of the heat pipe (number of rows, pressure drop, face velocity, heat pipe efficiency and heat recovery), the purity of working fluid, the slope of pipe, the evaporator length and the pipe thickness all affect the thermal efficiency of heat pipes, how it effects on heat recovery of each coil, power saving and other parameters. Wish to perform experiments on steady heat transfer to air flow that is in steady flow through a circular pipe. Our objective is to find the average heat transfer coefficient as a function of the various parameters in the system.

$$
\Pi_{1}=\frac{\mathbf{h D}}{\mathbf{K}} \text { known as the Nusselt number, } \Pi_{2}=\frac{\rho \mathbf{D V}}{\mu} \text { as the }
$$
Reynolds number Re, $\Pi_{3}=\frac{C_{p} \mu}{K}$, which is the prandtl number $\operatorname{Pr}, \Pi_{4}=\frac{L_{p i p e}}{\mathrm{D}}$. Therefore, dimensional analysis reveals that the 
Nusselt number must be a function of the Reynolds number, the Prandtl number, and an aspect ratio $\mathrm{L}_{\mathrm{pipe}} / \mathrm{D}$.

$$
\mathrm{Nu}=\phi\left(\operatorname{Re}, \operatorname{Pr}, \frac{L_{p i p e}}{D}\right)
$$

Then the average Nusselt number and heat transfer coefficient for all the tubes in the tube bank become

$$
\boldsymbol{h}=\frac{\boldsymbol{N} \boldsymbol{u}_{\boldsymbol{D}, \boldsymbol{N}_{L}} \boldsymbol{K}}{\boldsymbol{D}}\left(w / m^{2} \cdot C\right)
$$

Then the fluid exit temperature and the log mean temperature difference become

$$
\begin{gathered}
\boldsymbol{T}_{\boldsymbol{e}}=T_{s}-\left(T_{s}-T_{i}\right) \exp \left(\frac{-A_{s} h}{m C_{p}}\right) \\
\Delta \boldsymbol{T}_{\boldsymbol{i n}}=\frac{\left(T_{s}-T_{e}\right)-\left(T_{s}-T_{i}\right)}{\ln \left(\left(T_{s}-T_{e}\right) /\left(T_{s}-T_{i}\right)\right)}
\end{gathered}
$$

The rate of heat transfer can also be determined in a simpler way from

$$
\begin{gathered}
\boldsymbol{Q}_{\text {Sensible }}=m \cdot C_{p}\left(T_{e}-T_{i}\right)=h A_{s} \Delta T_{i n} \\
\boldsymbol{Q}_{\text {Latent }}=\boldsymbol{m} \boldsymbol{x} \boldsymbol{\Delta} \boldsymbol{X}(\text { Humidity ratio }) \\
\boldsymbol{Q}_{\text {Heat Recovered }}=\boldsymbol{Q}_{\text {Sensible }}+\boldsymbol{Q}_{\text {Latent }}
\end{gathered}
$$

The thermal resistance $(\mathrm{R})$ of the heat pipe is calculated using

$$
R=\frac{T_{e}-T_{c}}{Q} \text {, Where Te and Tc are temperature values at }
$$

the evaporator and condenser sections respectively and $\mathrm{Q}$ is the heat supplied to the heat pipe.

The Efficiency of HPHX is ratio of actual heat transfer to the maximum possible heat transfer. Since HPHX involves recovery of only sensible heat, therefore the efficiency of HPHX can also be defined as ratio of actual temperature drop to maximum possible temperature drop.

$$
\boldsymbol{\eta}_{H P H X}=\frac{T_{O A}-T_{L A}}{T_{O A}-T_{R A}}
$$

After we have finished our hand calculations as in above, now we will do the same calculation by using software which called SPC HPHR ( Version 2.5) from SPC company. we can calculate the volume, the dimension of the cooling coil, vertical heat pipe (number of rows, pressure drop, face velocity, heat pipe efficiency and heat recovery) by entering the values of both inlet and exhaust air characteristics and the suitable air flow $\mathrm{Q}$.

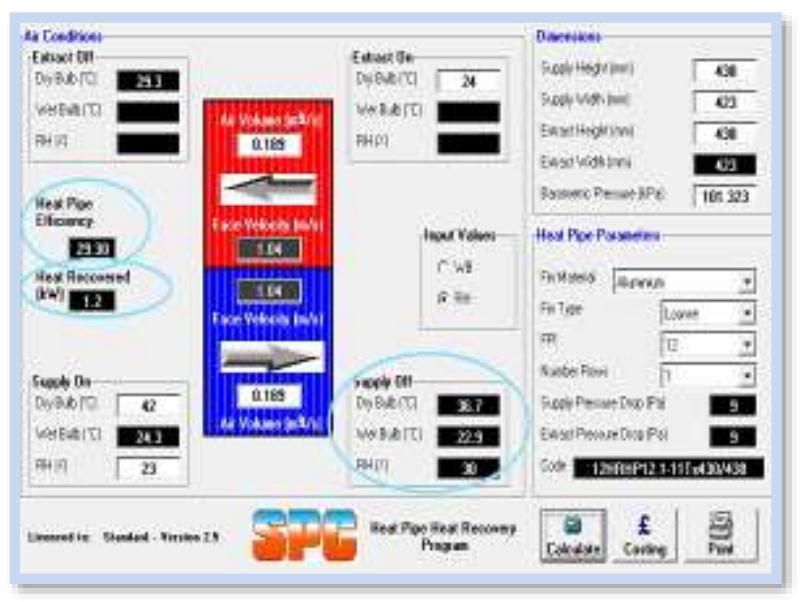

Figure (1) Output of Heat Pipe Heat Recovery program of SPC.

There are some parameters ( Input Data) to the selection programme as following :

Air volume $\left(\mathrm{m}^{3} / \mathrm{s}\right)$, supply on and extract on air temperatures $\left({ }^{\circ} \mathrm{C}\right)$, relative humidity of both supply and extract on air (\%), available dimension for supply and extract sides, fin material, types, number of fins per inch, number of rows.

We can do a comparison between analyses by hand calculations and also by using HPHR program software selection we can find The outlet temperature form the evaporating section, heat recovered and efficiency are the same for both calculations, so we will depend on Heat Pipe Heat recovery program selection for all of our calculations on positions with different conditions and parameters.

\section{EXPERIMENTAL SETUP}

In order to evaluate the performance of the suggested heat pipe heat exchanger with its inclination angles at different supply on temperatures, a test loop of the experimental set up, as shown in Figure (1). The system consists of the following:

Heat pipe heat exchanger in the system contains 16 copper tubes; each of them represents a heat pipe. Tubes shall be of refrigeration standard seamless copper $\mathrm{C} 106$ for heat exchanger use. Tubes diameter shall be a minimum of $9 \mathrm{~mm}$ with a grooved inner surface to enhance the internal surface area and prevent pooling of liquid. The minimum root thickness of the tube shall be $0.33 \mathrm{~mm}$.

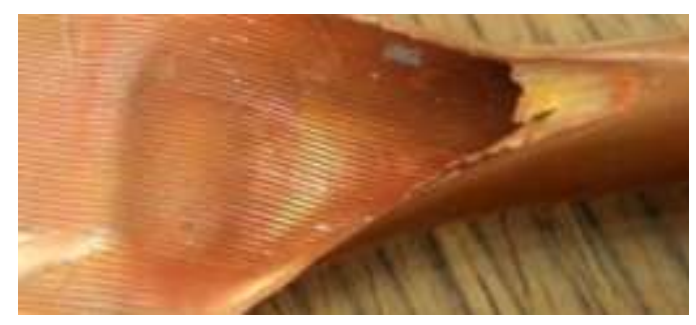

Figure (2) Inner grooved copper tube

The external fins shall be of aluminum with a minimum thickness of $0.12 \mathrm{~mm}$. The fins shall be of the rippled or 
louvered type to suit the application and spaced at such a distance as required by the conditions specified.

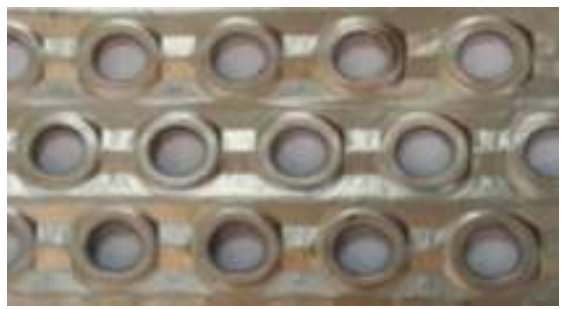

Figure (3) Aluminum Fins (Louvered type).

Casings shall be from galvanized sheet steel with a minimum thickness of $1.2 \mathrm{~mm}$. After the completion of manufacturing the heat pipe and get rid of all the impurities and oils by charging it with nitrogen, each pipe of the heat exchanger has been vacuumed by using a vacuum pump to be ensure sure that it became free of air and moisture.

Working fluid is charged to the evacuated section by charging needle connecting to gauge pressure test manifold and a refrigerant cylinder. Charging refrigerant for each pipe will be at $(45 \mathrm{psi}=3.1 \mathrm{Bar})$ with filling Ratio $(35 \%)$ that equal to 21.5 grams of refrigerant (R-22).

Supply and exhaust fans, which are selected by Nicotra software selection program and made of galvanized steel, which is balanced, have a high efficiency and a low-level noise and motors for both supply and exhaust fans have high efficiency, $1350 \mathrm{rpm}$, have five speeds and class (B) insulation which is designed due to National Electrical Manufacturers Association (NEMA) standard.

The inclination angle of the heat pipe are changed from vertical to horizontal position by using actuator (Belimo) that can control automatically in the pivot that used for changing the inclination angle.

The evaporator section is heated by supply on air flow that can achieved its conditions in the laboratory by using AHU with electric heaters and steam humidifier to get the required conditions of dry bulb temperature and relative humidity that added by the supply fan through the flexible duct to the empty isolated section (Armaflex isolation) connected to the evaporator section.

The condenser section is cooled by the exhaust air can achieved its conditions in the laboratory by using AHU with steam humidifiers which connected with sensors in the room to can get the required conditions of dry bulb temperature and control in the percentage of relative humidity. This air is added by exhaust fan through the flexible duct to the empty isolated section connected to the condenser section.

Fluid return is normally accomplished by gravity mechanism. Condensation of the refrigerant releases the heat absorbed in the evaporation phase resulting in heat transfer from the heat pipe hot end to the heat pipe cold end.

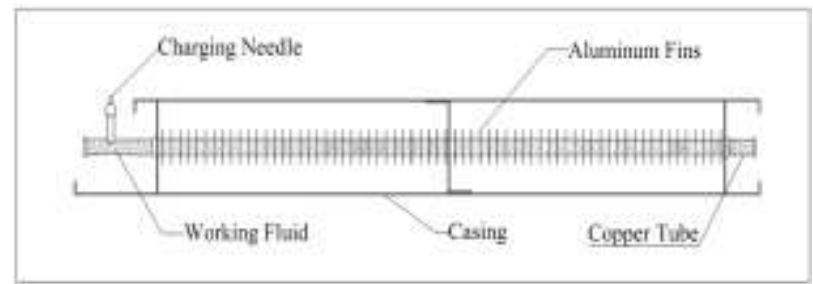

Figure (4) Heat pipe main structure components.

The experimental results were performed due to ASHRAE standard 1060(I-P) for performance rating of air-to-air exchangers for energy recovery ventilation equipment [1]. The experiments were conducted in EGAT Company's research and development laboratory, which is equipped with the latest measurements devices used in conducting experiments. The experimental procedures as following:

1- Adjust the refrigerant pressure in each pipe of heat pipe heat exchanger at the desired value.

2- The inclination angle of heat pipe should to be adjusting automatically to its predetermined value.

3- Adjust the supply on and extract on air conditions from dry bulb temperature and relative humidity as required in the design for both evaporator and condenser sections.

4- Record the measuring temperatures and relative humidity at each point on the supply plenum using thermocouples and anemometer after steady state conditions.
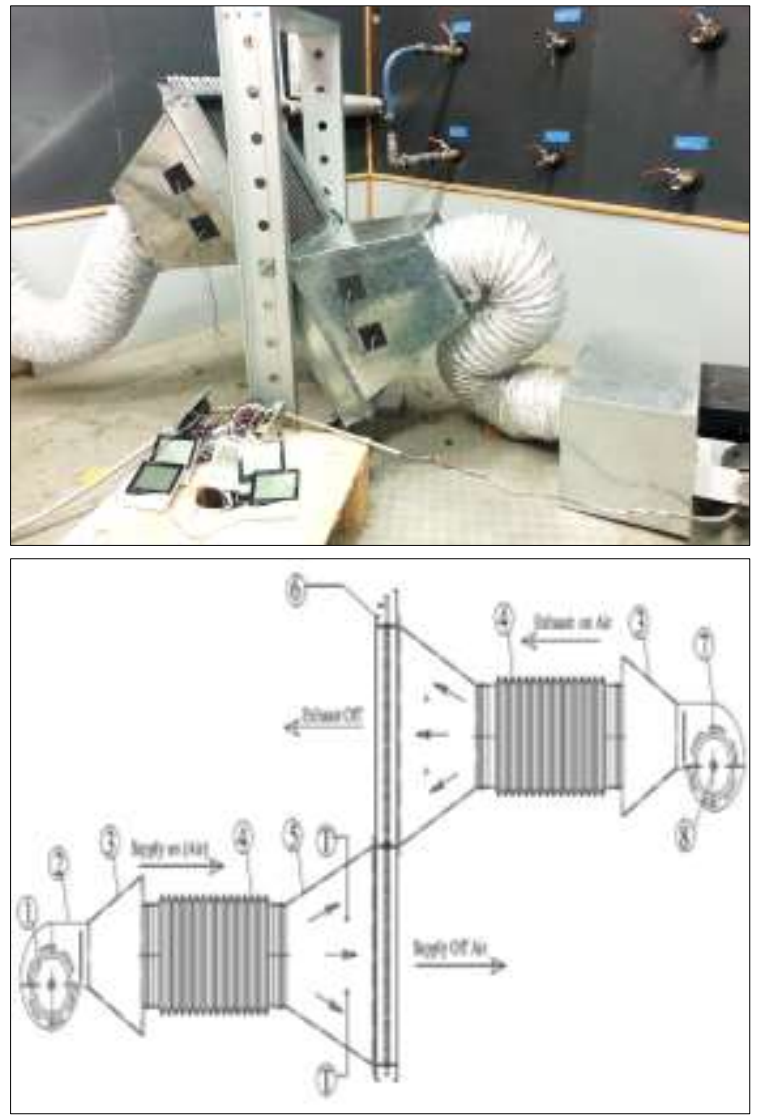

1) Supply Motor. 2) Supply Fan. $\quad$ 3) Empty Plenum

4) Flexible Duct. 5) Isolated Plenum. 6) Heat pipe. 7) Extract Fan 8) Extract Motor. T) Thermo-couple

Figure (5) Schematic diagram for the Heat pipe and the Experimental Test Rig. 


\section{RESULTS AND DISCUSSIONS}

A. Effects of inclination angle and supply on temperature on thermal efficiency.

Figure (6) shows the relation between heat pipe thermal efficiency and supply on temperatures. The heat pipe inclination angle of these results is taken as $0^{\circ}, 15^{\circ}, 30^{\circ}, 45^{\circ}$, $60^{\circ}, 75^{\circ}$ and $90^{\circ}$. It is illustrated from the figure that the heat pipe thermal efficiency sharply increases with supply on temperature increasing until a value of $40^{\circ} \mathrm{C}$ and then slightly increases with further increase in supply on temperature. This may be attributed to the fact that, the temperature of the working medium increases and hence more amount of heat can be removed in the condenser section.

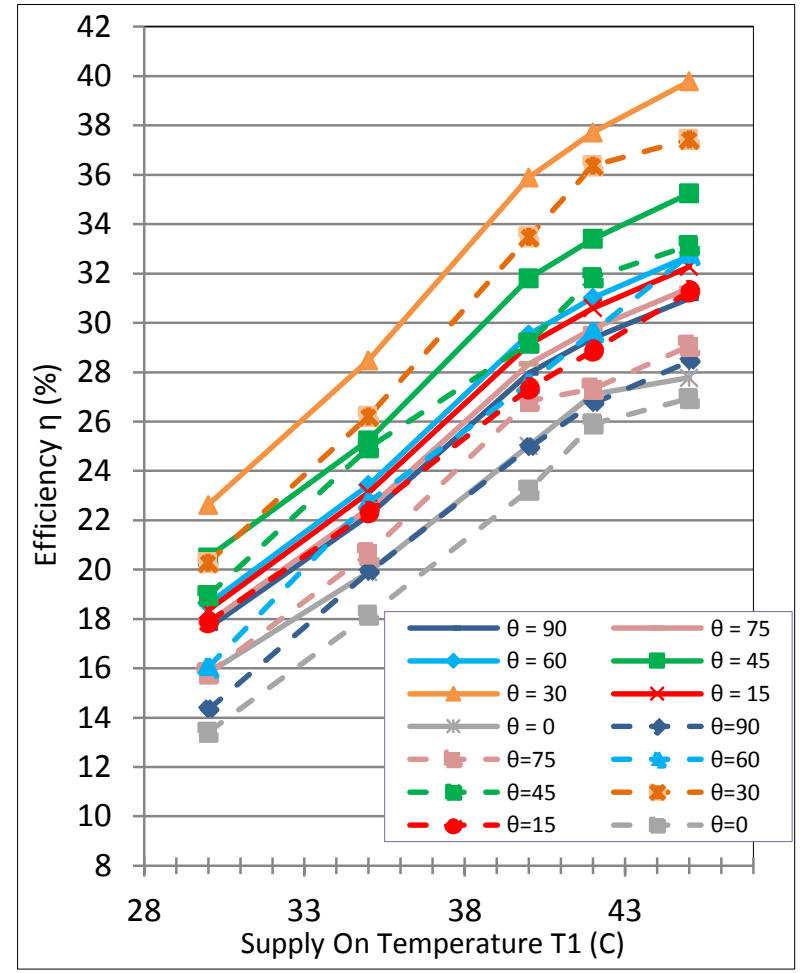

Figure (6): Relation between Thermal Efficiency and supply on temperatures at various inclination angles (Theoretical $\longrightarrow \&$ experimental - - -).

Figure (7) shows the relation between heat pipe thermal efficiency and inclination angle of heat pipe. The heat pipe inclination angle of these results is taken as $0^{\circ}, 15^{\circ}, 30^{\circ}, 45^{\circ}$, $60^{\circ}, 75^{\circ}$ and $90^{\circ}$ with different values of supply on temperature of $30^{\circ}, 35^{\circ}, 40^{\circ}, 42$ o and $45^{\circ} \mathrm{C}$ with constant air flow rate of $680(\mathrm{~m} 3 / \mathrm{hr})$. It is illustrated from the figure that the heat pipe efficiency increases with inclination angle until it reaches its maximum value at $30^{\circ}$ and then decreases with further increase in inclination angle.

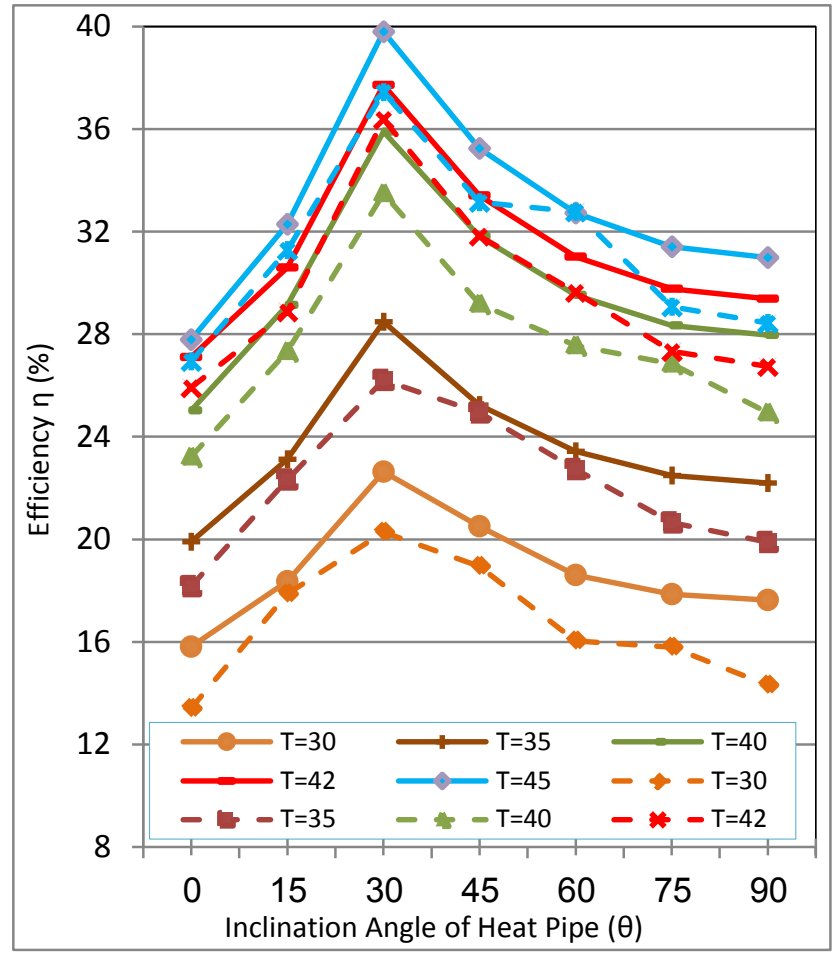

Figure (7): Relation between Thermal Efficiency and Inclination angle at various supplies on temperatures (Theoretical $\longrightarrow$ \& experimental - - -).

One can conclude from the figures that the theoretical and experimental results have the same trend of variation with higher values of the theoretical over these experimental.

It is also seen from the figure that the difference between theoretical and experimental value of heat pipe efficiency increases with the angle of inclination.

A general equation for the thermal efficiency $f(\eta)=(\theta$, T1) for different supply on temperatures and different inclination angles at constant air volume as following:

$\eta=(-0.0000004 \mathrm{~T} 1+0.00007) \theta^{3}+(-0.00002 \mathrm{~T} 1-$ $0.0095) \theta^{2}+(0.0035 \mathrm{~T} 1+0.361) \theta+(0.9275 \mathrm{~T} 1-14.36)$

\section{B. Effects of inclination angle and supply on temperature on heat recovered.}

Figure (8) shows the effect of supply on temperature on the heat recovered capacity. The heat pipe inclination angle of these results is taken as $0^{\circ}, 15^{\circ}, 30^{\circ}, 45^{\circ}, 60^{\circ}, 75^{\circ}$ and $90^{\circ}$. It is illustrated from the figure that the heat pipe heat recovered capacity slightly increases with supply on temperature until a temperature of $35^{\circ} \mathrm{C}$ and then sharply increases with further increase in supply on temperature. 


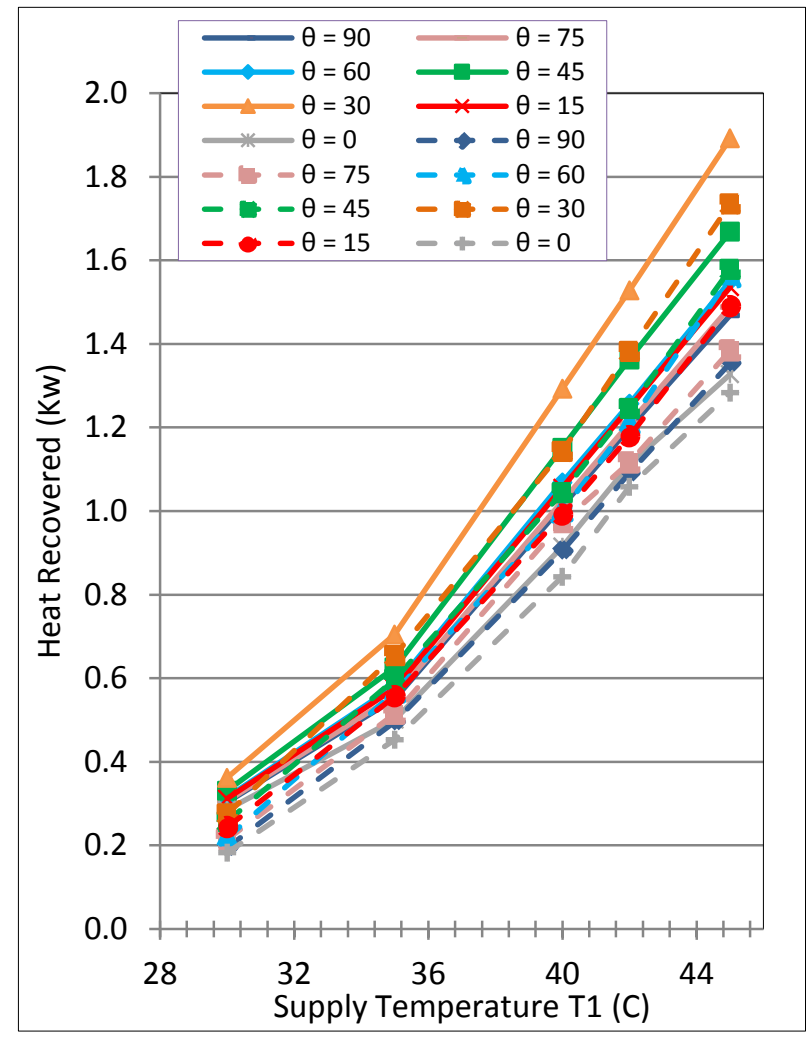

Figure (8): Relation between Heat Recovered and supply on temperatures at various inclination angles (Theoretical $\longrightarrow \&$ experimental - - -)

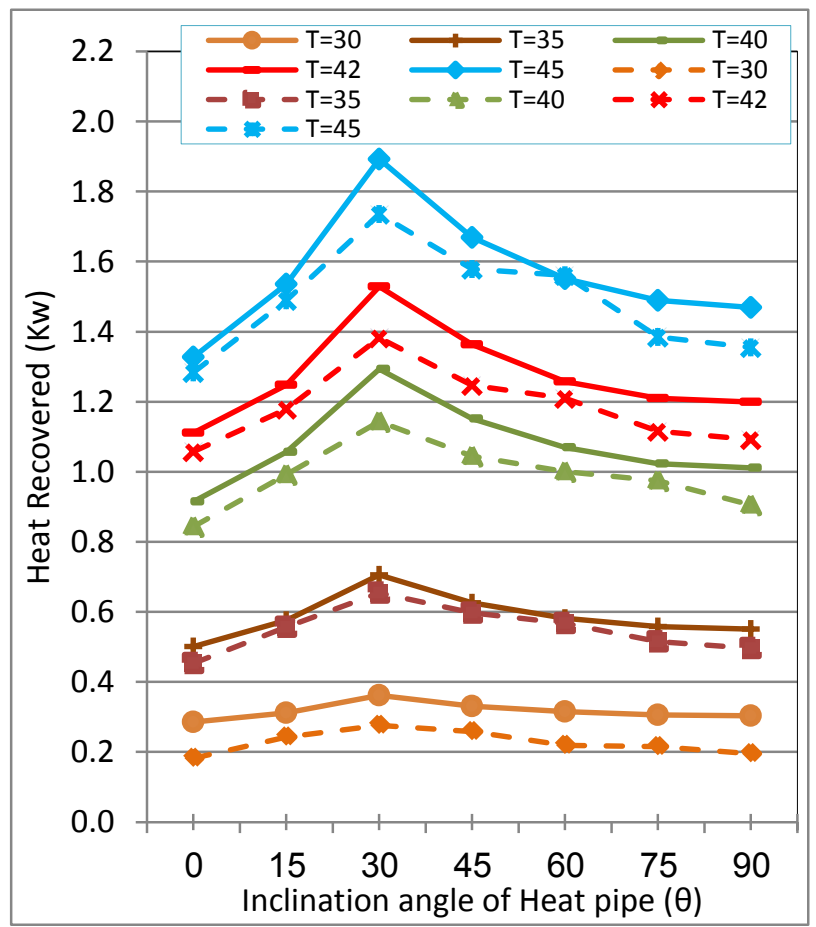

Figure (9): Relation between Heat Recovered and Inclination angle at various supplies on temperatures (Theoretical $\_\&$ experimental - - -)

Figure (9) shows the relation between the heat pipe heat recovered and inclination angle of heat pipe. The heat pipe inclination angle of these results is taken as $0^{\circ}, 15^{\circ}, 30^{\circ}, 45^{\circ}$, $60^{\circ}, 75^{\circ}$ and $90^{\circ}$ with different values of supply on temperature of $30^{\circ}, 35^{\circ}, 40^{\circ}, 42^{\circ}$ and $45^{\circ} \mathrm{C}$ at constant air flow rate of $680(\mathrm{~m} 3 / \mathrm{hr})$. It is illustrated from the figure that the heat pipe heat recovered capacity increases with inclination angle until it reaches its maximum value at $30^{\circ}$ and then decreases with further increase in inclination angle.

Also from figure (9) one can observe that the theoretical and experimental heat pipe heat recovered values have the same trend of variation. In the same time the theoretical values are higher than those of the experimental one. It is also seen from the figure that the difference between theoretical and experimental value of heat pipe heat recovered capacity increases with the supply on temperature. This may be because increasing supply on temperature, the heat pipe heat recovery increase, the temperature gradient through the heat pipe increases and consequently the generated vapor increases and moves vigorously into the condenser section. The return air flowing through the condenser absorbs this excessive heat and as a result, the heat recovered of the heat pipe increases.

\section{Effects of inclination angle and supply on temperature on supply off temperature.}

Figure (10) shows the relation between the supply off temperature and supply on temperatures, which takes the values of $30^{\circ}, 35^{\circ}, 40^{\circ}, 42^{\circ}$ and $45^{\circ} \mathrm{C}$. It is shown from the figure that the supply off temperature increases with supply on temperature.

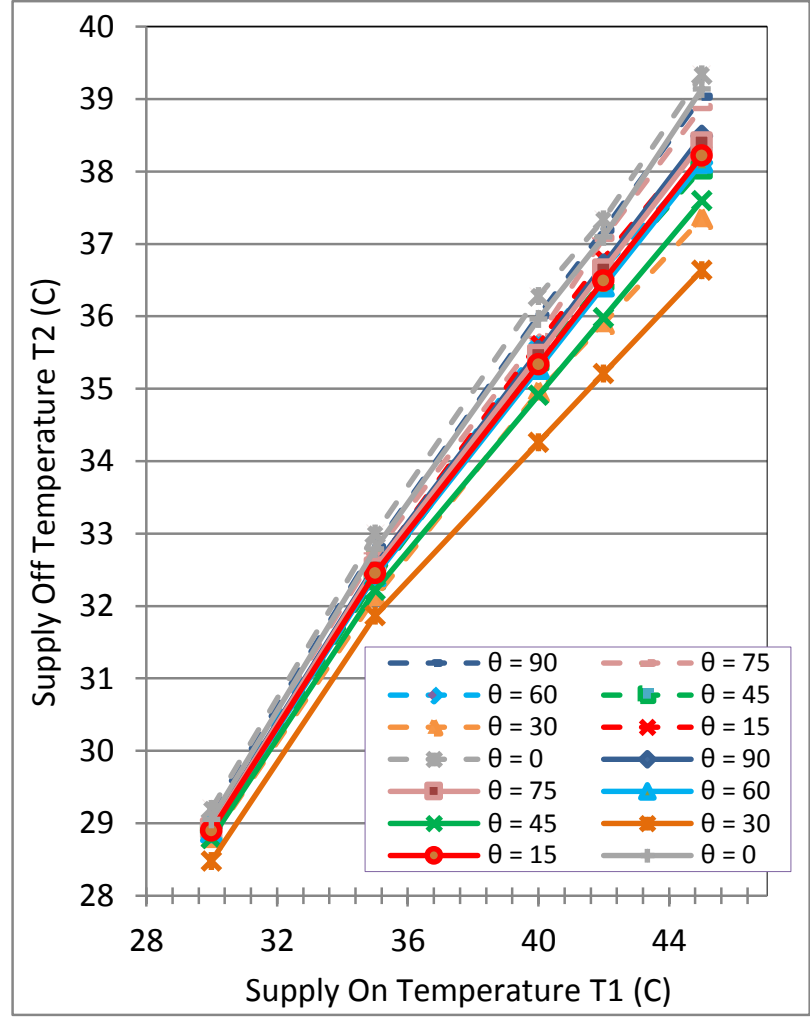

Figure (10): Relation between Supply off temperature and supply on temperatures at various inclination angles (Theoretical —\& experimental - $-)$. 


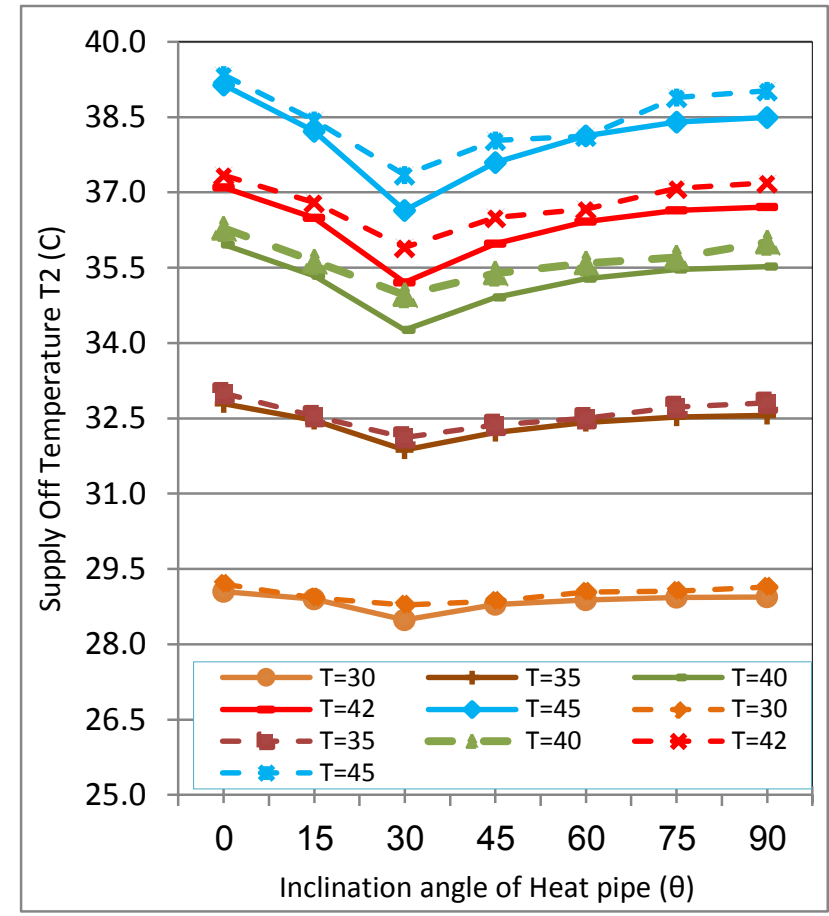

Figure (11): Relation between Supply of temperature and Inclination angle at various supplies on temperatures (Theoretical $-\&$ experimental - - -).

Figure (11) shows the effect of inclination angle on supply off temperature. The heat pipe inclination angle of these results is taken as $0^{\circ}, 15^{\circ}, 30^{\circ}, 45^{\circ}, 60^{\circ}, 75^{\circ}$ and $90^{\circ}$ with different values of supply on temperature of $30^{\circ}, 35^{\circ}, 40^{\circ}, 42$ ${ }^{\circ}$ and $45{ }^{\circ} \mathrm{C}$ with constant air flow rate of $680\left(\mathrm{~m}^{3} / \mathrm{hr}\right)$. It is shown from the figure that supply off temperature slightly decreases with the increase of inclination angle until it reaches its minimum value at $30^{\circ}$ and then decreases with further increase in inclination angle.

One can conclude from the figures that the theoretical and experimental supply off temperature has the same trend of variation with higher values of the experimental over these theoretical.

It is also seen from the figure that the difference between theoretical and experimental value of supply off temperature increases with the supply on temperature.

\section{Effects of inclination angle and supply on temperature on thermal resistance.}

Figure (12) shows the relation between thermal resistance and supply on temperatures. The supply on temperature of these results is taken as $30^{\circ}, 35^{\circ}, 40^{\circ}, 42^{\circ}$ and $45^{\circ} \mathrm{C}$ with different inclination angle and constant airflow rate. The figure illustrate that the heat pipe thermal resistance sharply decreases with supply on temperature increasing until a value of $40^{\circ} \mathrm{C}$ and then slightly decreases with further increase in supply on temperature.

Figure (13) shows the effect of inclination angle on thermal resistance of heat pipe. The heat pipe inclination angle of these results is taken as $0^{\circ}, 15^{\circ}, 30^{\circ}, 45^{\circ}, 60^{\circ}, 75^{\circ}$ and $90^{\circ}$ with different supply on temperature of $30^{\circ}, 35^{\circ}, 40^{\circ}, 42^{\circ}$ and $45^{\circ} \mathrm{C}$ with constant air flow rate of $680\left(\mathrm{~m}^{3} / \mathrm{hr}\right)$. The figure shows that the heat pipe thermal resistance decreases with the increase in inclination angle until it reaches its minimum value at $30^{\circ}$ and then slightly increases with further increase in inclination angle. This may be due to the higher rate of formation of liquid film inside the condenser at larger inclination angles leads to the increase of thermal resistance.

The thermal resistance $(R)$ of the heat pipe is calculated using $R=\frac{T_{e}-T_{c}}{Q}$, Where Te and Tc are temperature values at the evaporator and condenser sections respectively and $\mathrm{Q}$ is the heat supplied to the heat pipe.

One can conclude from the figures that the theoretical and experimental heat pipe thermal resistance has the same trend of variation with higher values of the theoretical over these experimental. It is also seen from the figure that the difference between theoretical and experimental value of heat pipe thermal resistance decreases with the supply on temperature increases and decreases with the angle of inclination.

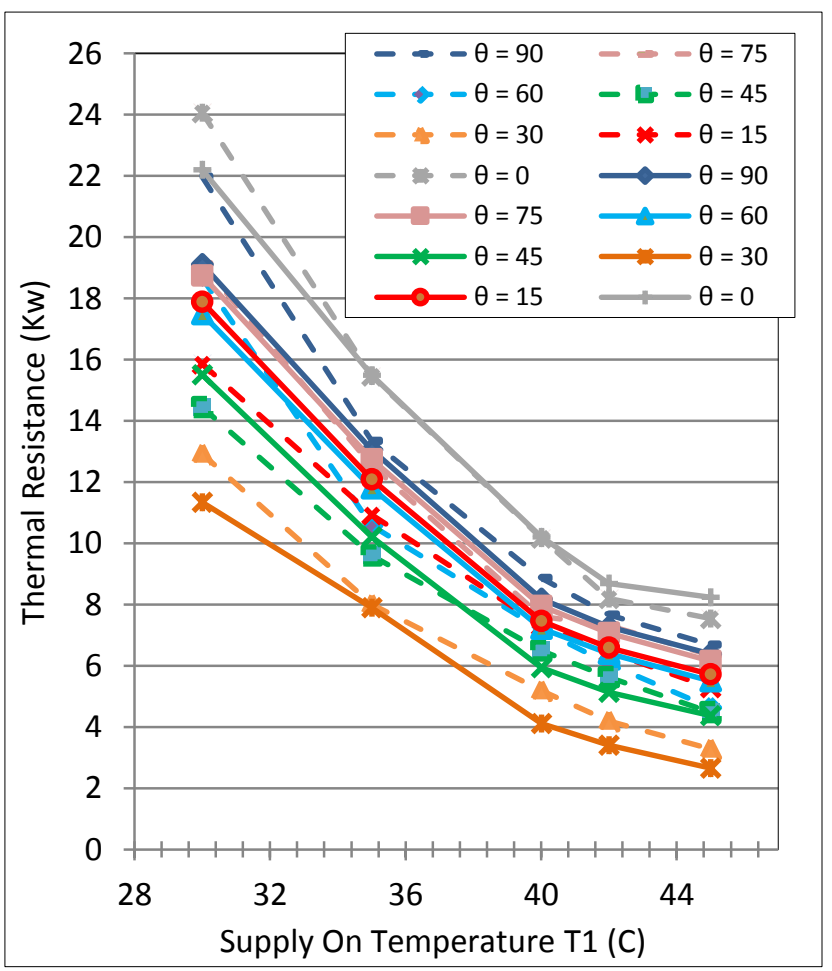

Figure (12): Relation between Thermal Resistance and supply on temperatures at various inclination angles (Theoretical $\longrightarrow \&$ experimental $---)$. 


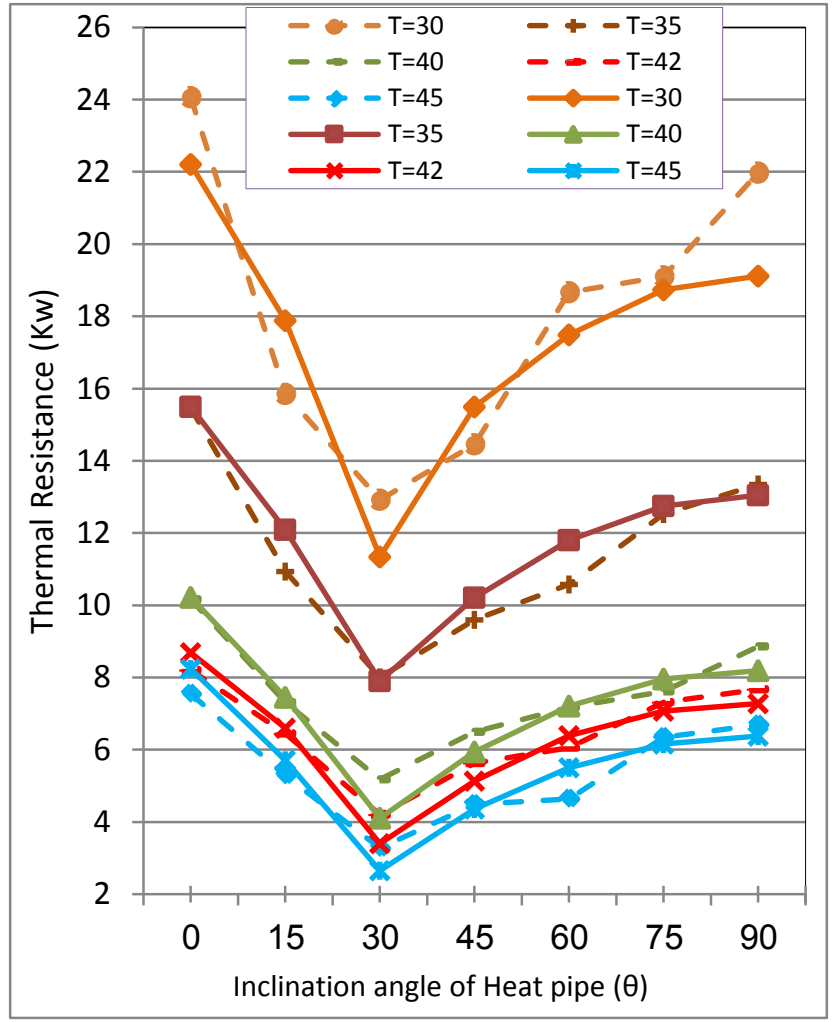

Figure (13): Relation between Thermal Resistance and Inclination angle at various supplies on temperatures (Theoretical —\& experimental - - -).

\section{COMPARISON BETWEEN PRESENT RESULTS AND OTHER RESULTS}

By comparison, our experimental results with experimental results carried out by Senthilkumar et al. [14]. It is illustrated from the figure that the heat pipe thermal efficiency slightly increases with inclination angle decrease until a value of $30^{\circ}$ and then slightly decreases with further decrease in Inclination angle. One can conclude from the figure that our experimental results and Senthilkumar et al. experimental results of heat pipe efficiency has the same trend of variation with higher values of Senthilkumar et al. results over our results. This mismatching (division percentage) is about (3.7-8.6) \% may be because some convergence between the both results of the form to be easily resolved by imposing a slightly different assumptions of fact and also because of the margin of error in the analysis of experimental results.

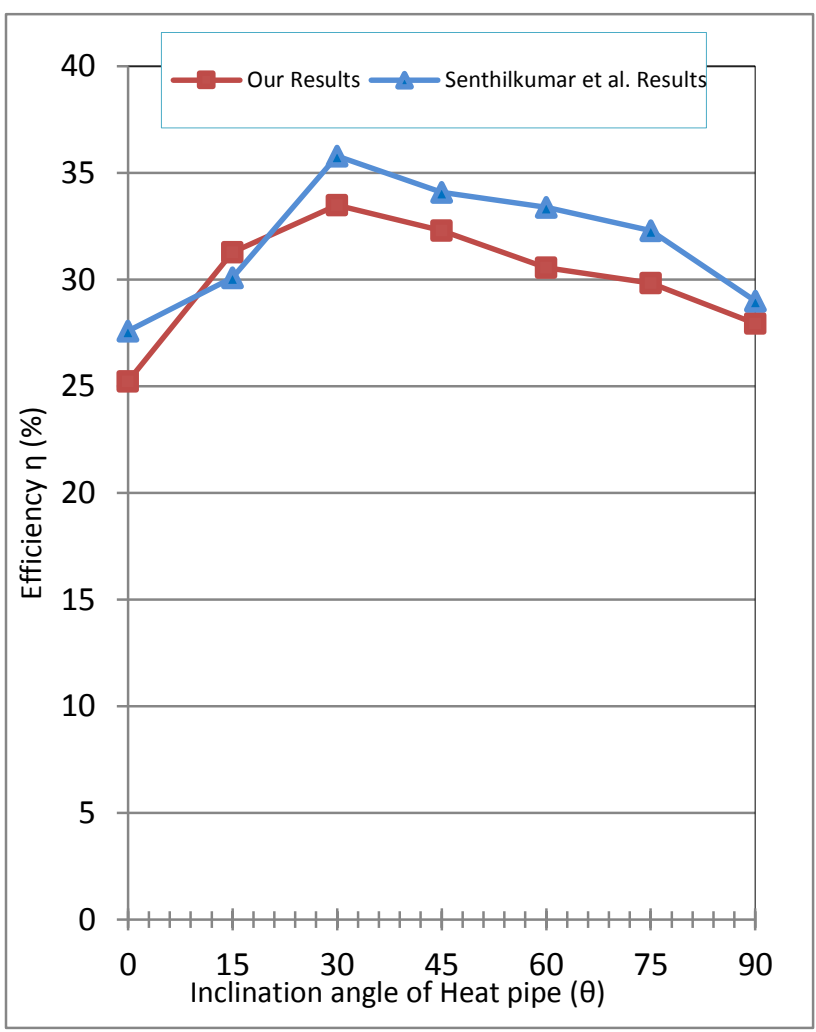

Figure (14): Relation between Thermal efficiency and inclination angle at various experimental results.

\section{CONCLUSION}

Based on the results of the experiments carried out to investigate the effect of tilt angle and supply on temperature on the performance of HPHX, following conclusions were recorded:

1) Heat pipe efficiency and heat recovered capacity are increased by increasing the inclination angle until reach its maximum values at $\left(\theta=30^{\circ}\right)$ and then decreased to reach its vertical position.

2) Supply off temperature and thermal resistance are decreased by increasing the inclination angle until reach its minimum values at $\left(\theta=30^{\circ}\right)$ and then increased to reach its horizontal position.

3) Heat pipe efficiency and heat-recovered capacity are increased by increasing the supply on temperature.

4) Supply off temperature and thermal resistance are decreased by increasing the supply on temperature.

\section{ACKNOWLEDGMENT}

I would like to give my special thanks and appreciation to EGAT Group (Egyptian German Air Treatment Co.).

\section{REFERENCES}

[1]. ASHRAE Standard 1060(I-P), Performance Rating of air to air exchangers for energy recovery ventilation equipment, 2013, American Society of Heating, Refrigerating and Air-Conditioning Engineers, Inc., 1791 Tullie Circle N.E., Atlanta, GA 30329, U.S.A..

[2]. R. Senthilkumar, S. Vaidyanathan and B. Sivaraman, 2011, "Performance Investigation of Heat Pipe Using Aqueous Solution of n- 
Pentanol with Different Inclinations", Journal of Mechanical Science and Technology, 25(4), 923-929.

[3]. W.Y. Saman, Performance of thermosyphon heat exchanger in an evaporative air conditioning system, 1993, in: Proceeding of the 5th Australasian Heat and Mass Transfer Conference, Brisbane.

[4]. J.K. McFarland, S.M. Jeter, S.I. Abdel-Khalik, Effect of heat pipe on dehumidification of a controlled air space, ASHRAE Transactions 102 (part 1) ,1996,132-139.

[5]. L. Shao, S.B. Riffat, Flow loss caused by heat pipe in natural ventilation stacks, Applied Thermal Engineering 17 (4) ,1997, 393-399.

[6]. F.J.R. Martinez, M.A. Alvarez-Guerra Plasencia, E. Velasco Gomez, F.V. Diez, R.H. Martin, Design and experimental study of mixed energy recovery system, heat pipe and indirect evaporative equipment for air conditioning, Energy and Buildings 35 , 2003, 1021-1030.

[7]. S.B. Riffat, J. Zhu, Mathematical model of indirect evaporative cooler using porous ceramic and heat pipe, Applied Thermal Engineering 24, 2004, 457-470.

[8]. Mostafa Abd El-Baky and Mousa M. Mohamed, "Heat Pipe Heat Exchanger for Heat Recovery in Air Conditioning," ASME-ATI, "Energy: Production, Distribution and Conservation", Milan, Italy, Vol. 2, May. 2006, pp. 659-668.

[9]. S. Tushar Jadhav and M. Mandar Lele, "A Case Study On Energy Savings In Air Conditioning System By Heat Recovery Using Heat Pipe Heat Exchanger", International Journal of Research in Engineering and Technology, Vol. 3, Jan. 2014.

[10]. K. Beckert, H. Herwig, Inclined air to air heat exchangers with heat pipes: comparing experimental data with theoretical results, in: Proceedings of the 31st Intersociety Energy Conversion Engineering Conference, vol. 2, Washington DC, USA, 1996, pp. 1441-1446.

[11]. S.A. Said, B.A. Akash, Experimental performance of a heat pipe, International Communications in Heat and Mass Transfer 26 (5), 1999, 679-684.
[12]. M.H. Kim, S. Song, C.W. Bullard, Effect of inlet humidity condition on the airside performance of an inclined brazed aluminum evaporator, International

[13]. Journal of Refrigeration 25, 2002, 611-620.

[14]. Y.H. Yau, Experimental thermal performance study of an inclined heat pipe exchanger operating in high humid tropical HVAC systems, International Journal of Refrigeration 30, 2007, 1143-1152.

[15]. R. Senthilkumar, S. Vaidyanathan and B. Sivaraman, 2012, "Effect of inclination angle in Heat pipe performance using copper nanofluid," Indian Journal of Science and Technology Vol. 3(6), 702-706.

[16]. J.H. Huh, M.J. Brandemuehl, Optimization of air-conditioning system operating strategies for hot and humid climates, Energy and Buildings 40 (2008) 1202- 1213.

[17]. Y.H. Yau, The use of a double heat pipe heat exchanger system for reducing energy consumption of treating ventilation air in an operating theatre - a full year energy consumption model simulation, Energy and Buildings 40 (2008) 917-925.

[18]. M. Ahmadzadehtalatapeh, "An air-conditioning system performance enhancement by using heat pipe based heat recover y technology", ScientiaIranica, Transactions B: Mechanical Engineering., Vol. 20, Jan. 2013, pp. 329-336.

[19]. R. Boukhanouf, A. Alharbi, O. Amer and H. G. Ibrahim, "Experimental and Numerical Study of a Heat Pipe Based Indirect Porous Ceramic Evaporative Cooler," International Journal of Environmental Science and Development, Vol. 6, Feb.2015.

[20]. L. Sagar, B. Vijay and M. Jagadale, "Energy Saving of Window Air Conditioning System Using Heat Pipes and Dedicated Outside - Air System," IJSART - volume 1 Issue 8 -AUGUST 2015. 